\title{
Acceptor-rich bulk heterojunction polymer solar cells with balanced charge mobilities
}

\author{
Tingting Zhu ${ }^{\text {a, b }}$, Yongchao Zhang a , Yonghai Li ${ }^{\text {a, }}{ }^{* *}$, Xin Song ${ }^{b}$, Zhe Liu ${ }^{b}$, Shuguang Wen ${ }^{a}$, \\ Xichang Bao ${ }^{a}$, Mingliang Sun ${ }^{\text {b, * }}$, Renqiang Yang ${ }^{\text {a, } * * *}$ \\ a CAS Key Laboratory of Bio-based Materials, Qingdao Institute of Bioenergy and Bioprocess Technology, Chinese Academy of Sciences, Qingdao 266101, \\ China \\ ${ }^{\mathrm{b}}$ Institute of Material Science and Engineering, Ocean University of China, Qingdao 266100, China
}

\section{A R T I C L E I N F O}

\section{Article history:}

Received 13 July 2017

Received in revised form

24 August 2017

Accepted 25 August 2017

Available online 4 September 2017

\section{Keywords:}

Wide band-gap

Acceptor-rich blend

Polymer solar cells

Balanced charge mobilities

\begin{abstract}
A B S T R A C T
In this work, we reported efficient polymer solar cells with balanced hole/electron mobilities tuned by the acceptor content in bulk heterojunction blend films. The photovoltaic cells were fabricated with two new wide band-gap D-A polymers PBDDIDT and PBDDIDTT as the donor material. The molecular conformations of new polymers are carefully evaluated by theoretical calculations. The results of photovoltaic studies show that two devices reach their optimal conditions with rich $\mathrm{PC}_{71} \mathrm{BM}$ content up to $80 \%$ in blend films, which is uncommon with most of reported PSCs. The as-cast devices based on PBDDIDT and PBDDIDTT reveal good photovoltaic performance with PCE of $7.04 \%$ and $6.40 \%$, respectively. The influence of $\mathrm{PC}_{71} \mathrm{BM}$ content on photovoltaic properties is further detailed studied by photoluminescence emission spectra, charge mobilities and heterojunction morphology. The results exhibit that more efficient charge transport between donor and acceptor occurs in rich $\mathrm{PC}_{71} \mathrm{BM}$ blend films. Meanwhile, the hole and electron mobilities are simultaneously enhanced and afford a good balance in rich $\mathrm{PC}_{71} \mathrm{BM}$ blend films (D/A, 1:4) which is critical for the improvement of current density and fill factors.
\end{abstract}

(C) 2017 Elsevier B.V. All rights reserved.

\section{Introduction}

During the past decade, polymer solar cells (PSCs) with bulk heterojunction (BHJ) structure have made great achievements owing to their low-cost, low weight and easy fabrication of large area devices [1-4].The optoelectronic properties of active-layer materials of PSCs with blend of donor material and acceptor material largely determined the power conversion efficiencies (PCEs) of solar cells. Up to date, the study of PSCs has achieved great progress with PCEs exceeding $10 \%$ in single- and multi-junction bulk heterojunction (BHJ) devices [5-10]. The electron acceptors including fullerene derivatives $\left(\mathrm{PC}_{61} \mathrm{BM}, \mathrm{PC}_{71} \mathrm{BM}\right.$ et al.) and fullerene-free n-type semiconductors (N2200, ITIC et al.) have been developed and proved efficient [11-16]. To match well with special acceptor materials, donor materials play an important role and the

\footnotetext{
* Corresponding author.

** Corresponding author.

*** Corresponding author.

E-mail addresses: liyh@qibebt.ac.cn (Y. Li), mlsun@ouc.edu.cn (M. Sun), yangrq@ qibebt.ac.cn (R. Yang).
}

molecular structures and basic optoelectronic properties should be carefully regulated.

Donor-acceptor (D-A) conjugated polymers composed of electron-donating unit (D) and electron-accepting unit (A) are widely investigated as donor materials for easy-tuning of frontier energy levels, absorption spectra and charge mobilities via construction of intramolecular charge transfer (ICT) effect [17,18]. To harvest more solar photons, narrow band-gap (NBG, $E_{\mathrm{g}}<1.8 \mathrm{eV}$ ) polymers with broad absorption spectra were designed and intensively studied. PSCs based on narrow band-gap polymers can exhibit favorable short-circuit current densities ( $J_{S C}$ ) benefiting from the broad and strong ICT absorption bands, yet the devices often exhibit decreased open-circuit voltages $\left(V_{\mathrm{OC}}\right)$ owing to the high-lying highest occupied molecular orbitals (HOMO). For example, the D-A polymers composed of strong electron-accepting diketopyrrolopyrrole (DPP) unit often possess narrow band-gaps around $1.40 \mathrm{eV}$ and broad absorption [19-21]. DPP-based D-A polymers reported by Janssen exhibit decent $J_{\mathrm{SC}}$ of $15.9 \mathrm{~mA} \mathrm{~cm}{ }^{-2}$, relatively low $V_{\mathrm{OC}}$ of $0.75 \mathrm{~V}$ and the overall power conversion efficiencies (PCEs) of 8.0\% [22]. Furthermore, Janssen and coworkers reported a series of small-band gap D-A polymers between $1.13 \mathrm{eV}$ 
and $1.34 \mathrm{eV}$, composed of strong electron-donating dithieno[3,2$\left.b: 2^{\prime}, 3^{\prime}-d\right]$ pyrrole (DTP) unit and DPP unit. The PSCs devices reveal high near-infrared photo-response, presenting particularly high $J_{S C}$ up to $23.0 \mathrm{~mA} \mathrm{~cm} \mathrm{~cm}^{-2}$; while low $V_{\mathrm{OC}}$ of $0.44 \mathrm{~V}$ are obtained, leading to a moderate efficiency of 5.3\% [23]. Yan and coworkers developed novel narrow band-gaps D-A polymers around $1.6 \mathrm{eV}$ based on difluorobenzothiadiazole (ffBT), the resulting PSCs exhibit high $J_{S C}$ up to $18.8 \mathrm{~mA} \mathrm{~cm}^{-2}$, enhanced $V_{\mathrm{OC}}$ of $0.77 \mathrm{~V}$ and state of the art PCE of $10.8 \%$ [24]. Nevertheless, the open-circuit voltages of photovoltaic devices based on narrow band-gap polymers are difficult to be further improved which inevitably restrict the further development of polymer solar cell efficiencies.

To solve the above challenges, medium band-gap (MBG, $E_{\mathrm{g}}: 1.6-1.8 \mathrm{eV}$ ) and wide band-gap (WBG, $E_{\mathrm{g}}>1.8 \mathrm{eV}$ ) D-A polymers were designed to explore a balance between $J_{S C}$ and $V_{O C}$ of PSCs. Currently, benzodithiophene (BDT) moieties and analogues including one-dimension (1D), two-dimension (2D) and asymmetric 1D-2D derivatives are efficient electron-donating building blocks to construct medium or wide band-gap D-A photovoltaic donor materials, due to its high stability against oxidation ability and planar molecular framework [25-30]. Recently, our group developed a series of D-A polymers based on asymmetric 1D-2D BDT derivatives to combine the strength of both 1D and 2D BDT based polymers. Among them, the polymer PBDT $\beta$ NPFBT blend with $\mathrm{PC}_{71} \mathrm{BM}$ exerts high $J_{S C}$ of $15.53 \mathrm{~mA} \mathrm{~cm} \mathrm{~cm}^{-2}$ and greatly enhanced $V_{\mathrm{OC}}$ of $0.89 \mathrm{~V}$ compared to NBG polymer based devices, leading to the excellent PCE up to 9.80\% [31]. Moreover, the MBG and WBG BDT based D-A polymers also demonstrate impressive applications in fullerene-free solar cells with small molecular and polymeric n-type semiconductors as acceptors [32,33].

Besides, fused ring ladder-type units are another classic building blocks to design D-A polymers for the decent coplanarity of polymer backbones which could enhance the interchain interactions and lead to higher hole mobility. For example, indacenodithiophene (IDT) and indacenodithieno[3,2-b]thiophene (IDTT) have been proved highly efficient as electron-donating moieties to design A-D-A small molecular fullerene-free acceptor materials [34-37]. The PCEs of polymer solar cells based on these fullerene- free acceptors have reached 13\% [38].In contrast, the D-A polymers with IDT or IDTT as the electron-donating moiety exhibit relatively low performance of PCE around 8\% [39-45].Yang's group reported two D-A conjugated polymers with IDT and IDTT as electrondonating moieties and the polymers possess wide optical energy band-gaps over $2.0 \mathrm{eV}$ as well as high hole mobility up to $10^{-3}$ $\mathrm{cm}^{2} \mathrm{~V}^{-1} \mathrm{~s}^{-1}$ and PCE exceeding 7\% [39]. Wang and coworkers reported a series of MBG IDT based D-A polymers with band-gaps around $1.75 \mathrm{eV}$, and the fabricated devices exhibit high performance with PCE of 7.8\% [40,41]. Very recently, Zheng's group reported a WBG polymer PIDTBTO-TT with PCE up to $8.15 \%$, which represents the highest solar cell efficiency achieved with IDT-based polymers so far [45]. These results demonstrate that IDT and IDTT moieties are promising building blocks for MBG and WBG D-A conjugated donor materials for the suitable electron-donating abilities and favorable molecular planarity.

Herein, to further investigate the photovoltaic performance of IDT/IDTT based polymers, we select relatively weak electronwithdrawing moietybenzo[1,2-c:4,5-c']dithiophene-4,8-dione (BDD) to couple weak electron-donating moiety IDT and IDTT and synthesize two wide band-gap D-A conjugated polymers PBDDIDT and PBDDIDTT with optical band-gap over $1.85 \mathrm{eV}$. Two polymers show similar absorption profiles which are synthetically determined by different polymer structures and distortion dihedral angles between $\mathrm{D}$ and $\mathrm{A}$ moieties. Polymer solar cells were fabricated with $\mathrm{PC}_{71} \mathrm{BM}$ as acceptor material. The results reveal that both additive-free devices based on PBDDIDT and PBDDIDTT exhibit favorable photovoltaic properties with PCE up to $7.04 \%$ and $6.40 \%$, respectively. The photovoltaic performance based on PBDDIDT is one of the highest efficiencies achieved with WBG IDT-based polymers. Notably, the polymer/PC ${ }_{71} \mathrm{BM}$ weight ratios have a significant impact on FF values and fullerene-rich devices exert better performance when the optimal weight ratios for two devices are determined to be 1:4. This is very different from other IDT-based polymer devices and most of PSCs. The correlations between donor/acceptor weight ratios and fill factors are investigated and proved to be mainly affected by high and balanced hole/electron charge transport. Photoluminescence (PL) spectra were carried out
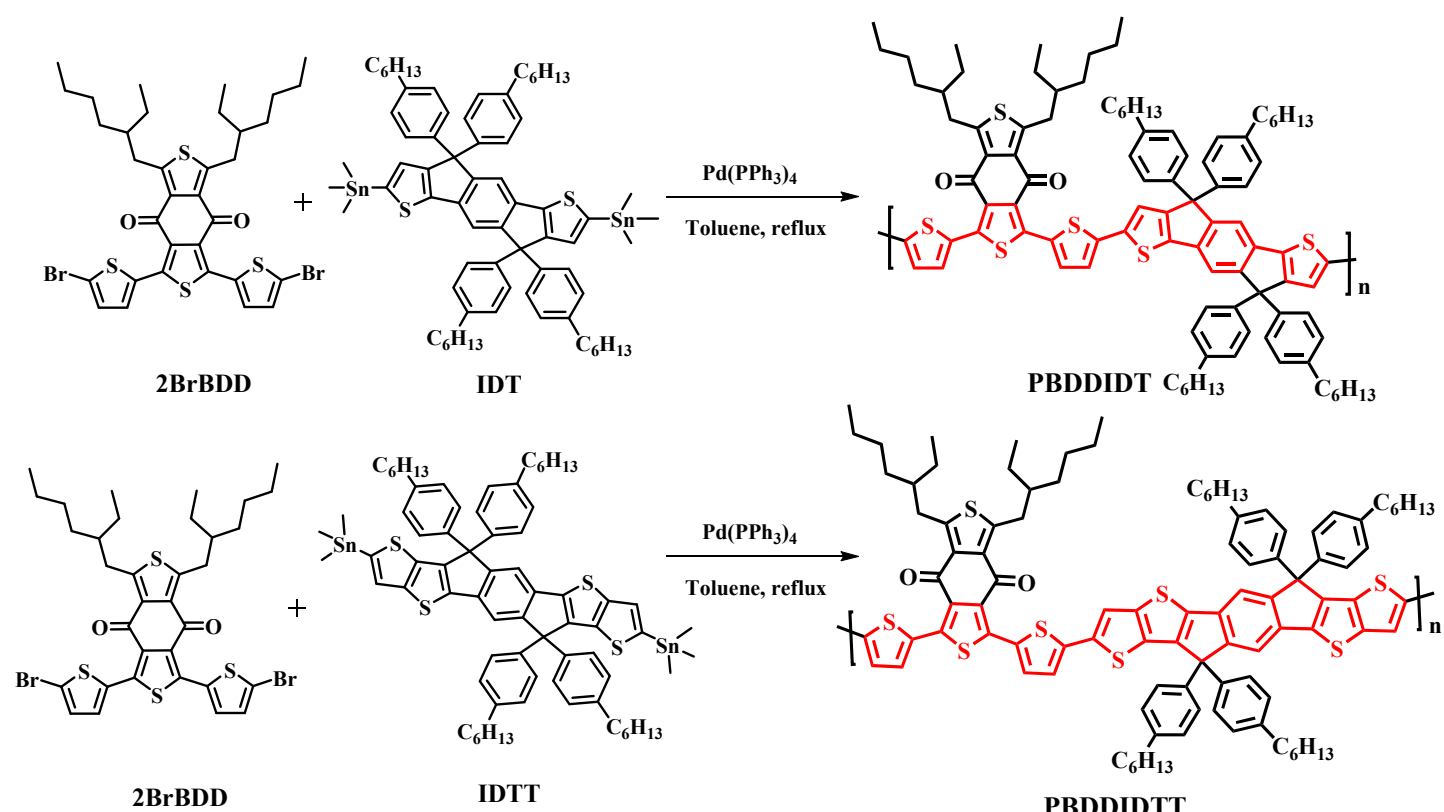

Scheme 1. Synthesis and chemical structures of PBDDIDT and PBDDIDTT. 
Table 1

Decomposition temperatures, molecular weights, optical properties and frontier energy levels of polymers.

\begin{tabular}{|c|c|c|c|c|c|c|c|c|}
\hline \multirow[t]{2}{*}{ Polymers } & \multirow{2}{*}{$\frac{T_{\mathrm{d}}}{\left({ }^{\circ} \mathrm{C}\right)^{\mathrm{a}}}$} & \multirow{2}{*}{$\frac{M_{\mathrm{n}}}{(\mathrm{kDa})}$} & \multirow[t]{2}{*}{ PDI } & \multicolumn{2}{|l|}{$\lambda_{\max }(\mathrm{nm})$} & \multirow{2}{*}{$\frac{E_{\mathrm{g}}^{\mathrm{opt}}}{(\mathrm{eV})^{\mathrm{b}}}$} & \multirow{2}{*}{$\frac{\mathrm{HOMO}^{\mathrm{cV}}}{(\mathrm{eV})^{\mathrm{c}}}$} & \multirow{2}{*}{$\frac{\mathrm{LUMO}^{\mathrm{cV}}}{(\mathrm{eV})^{\mathrm{c}}}$} \\
\hline & & & & solution & film & & & \\
\hline PBDDIDT & 396 & 21.8 & 2.15 & 547 & 570 & 1.85 & -5.62 & -3.77 \\
\hline PBDDIDTT & 385 & 25.6 & 1.98 & 545 & 560 & 1.86 & -5.65 & -3.79 \\
\hline
\end{tabular}

${ }^{a}$ Measured under $\mathrm{N}_{2}$ atmosphere.

b Calculated based on the onset of thin films absorption spectra.

c Calculated from cyclic voltammograms curves.

to study exciton separation/transport and detailed morphological nature was further analyzed by atomic force microscopy (AFM) and transmission electron microscopy (TEM).

\section{Results and discussions}

\subsection{Synthesis and characterization}

The synthetic route of polymer PBDDIDT and PBDDIDTT are shown in Scheme 1. Polymers were prepared by Stille polymerization in the presence of $\mathrm{Pd}\left(\mathrm{PPh}_{3}\right)_{4}$ as catalyst and the detailed synthetic procedures are provided in Experimental Section. The chemical structures of two polymers were confirmed by ${ }^{1} \mathrm{H}$ NMR spectroscopy. Two Polymers exhibit favorable solubility (>20 mg/ $\mathrm{mL}$ ) in common solvents such as tetrahydrofuran (THF), chloroform, toluene, chlorobenzene $(\mathrm{CB})$ and $o$-dichlorobenzene $(0-\mathrm{DCB})$ at room temperature. As shown in Fig. S1 and Fig. S2 (Supporting Information), the number-average molecular weights $\left(M_{n}\right)$ and polydispersity index (PDI) of PBDDIDT and PBDDIDTT are estimated by gel permeation chromatography (GPC) with tetrahydrofuran $\left(40^{\circ} \mathrm{C}\right)$ as the eluent and determined to be $21.8 \mathrm{kDa}$ and $25.6 \mathrm{kDa}$ as well as 2.15 and 1.98 , respectively, and the relevant data are collected in Table 1. As shown in Fig. S3 (Supporting Information), the thermal properties of two polymers were measured by thermogravimetric analysis (TGA) and the decomposition temperatures $\left(T_{\mathrm{d}}\right)$ with $5 \%$ weight loss for PBDDIDT and PBDDIDTT are confirmed to be $396{ }^{\circ} \mathrm{C}$ and $385^{\circ} \mathrm{C}$, respectively, which suggest that the thermal stability of the polymers is good enough for application in PSCs devices.

\subsection{Optical properties and frontier energy levels}

The UV-vis absorption spectra of PBDDIDT and PBDDIDTT are measured in dilute chloroform solution and as thin films and the corresponding data are listed in Table 1. As shown in Fig. 1a, two polymers exhibit similar absorption profiles with broad absorption from $300 \mathrm{~nm}$ to $700 \mathrm{~nm}$. The minor bands around $425 \mathrm{~nm}$ should be attributed to $\pi-\pi^{*}$ transition and the major bands around $550 \mathrm{~nm}$ probably originate from intramolecular charge-transfer (ICT) effect between the electron-donating and electronwithdrawing units $[46,47]$. Furthermore, compared to the absorption spectra in solution, thin film spectra are red-shifted by 20-30 nm induced mainly by the enhanced intermolecular interactions in solid states [48]. Unexpectedly, the spectra of polymer PBDDIDTT with larger conjugated backbones show slightly hypochromatic shift compared to PBDDIDT which probably be correlated with the planarity of polymer backbones as studied below. Also, the absorption maximum (from solution to film state) of PBDDIDT is red-shifted by $23 \mathrm{~nm}$, larger than that of PDBBIDTT $(15 \mathrm{~nm})$, which may be correlated to the better solid packing of PBDDIDT resulting from its more planar structure. From the onset of thin film absorption spectra, the optical band-gap of polymer PBDDIDT and PBDDIDTT were calculated to be $1.85 \mathrm{eV}$ and $1.86 \mathrm{eV}$, respectively.

Electrochemical cyclic voltammetry (CV) measurement was carried out to measure the oxidation/reduction potentials and further estimate highest occupied molecular orbital (HOMO) and lowest unoccupied molecular orbital (LUMO) energy levels of polymers. The relevant data were collected in Table 1. As shown in Fig. 1b, both PBDDIDT and PBDDIDTT show qusi-reversible oxidation process. The oxidation onset potentials $\left(E_{\mathrm{Ox}}\right)$ of PBDDIDT and PBDDIDTT referenced to $\mathrm{Ag} / \mathrm{AgCl}\left(\mathrm{Ag} / \mathrm{Ag}^{+}\right)$were determined to be $1.21 \mathrm{~V}$ and $1.24 \mathrm{~V}$, respectively. Calculated from the equation: $E_{\text {HOMO }}=-\mathrm{e}\left(\varphi_{\mathrm{ox}}+4.8-\varphi_{1 / 2}, \mathrm{FeCp} 2\right)(\mathrm{eV})$, the HOMO energy levels of PBDDIDT and PBDDIDTT are identified to be $-5.62 \mathrm{eV}$ and $-5.65 \mathrm{eV}$, respectively [49]. Based on the optical band-gaps, LUMO energy levels are calculated to be $-3.77 \mathrm{eV}$ and $-3.79 \mathrm{eV}$ for PBDDIDT and PBDDIDTT, respectively.

\subsection{Theoretical calculations}

To further understand the molecular conformations of PBDDIDT and PBDDIDTT, theoretical calculation was employed by using density functional theory (DFT) at the B3LYP/6-31G* level. The long alkyl side chains were replaced with methyl groups to reduce the calculation time. As shown in Fig. 2, the dihedral angels between BDD core and neighboring thiophene units (blue arrows in Fig. 2) are close in both polymers. While great difference of dihedral angels between IDT/IDTT unit and neighboring thiophene unit are observed (red arrows in Fig. 2). The torsion angles between IDTT and thiophene $\left(16.13^{\circ}\right)$ is more than two times larger than that of IDT and thiophene ( $7.61^{\circ}$ ). The large torsion of PBDDIDTT backbone will negatively affect the effective extend of conjugated degree,
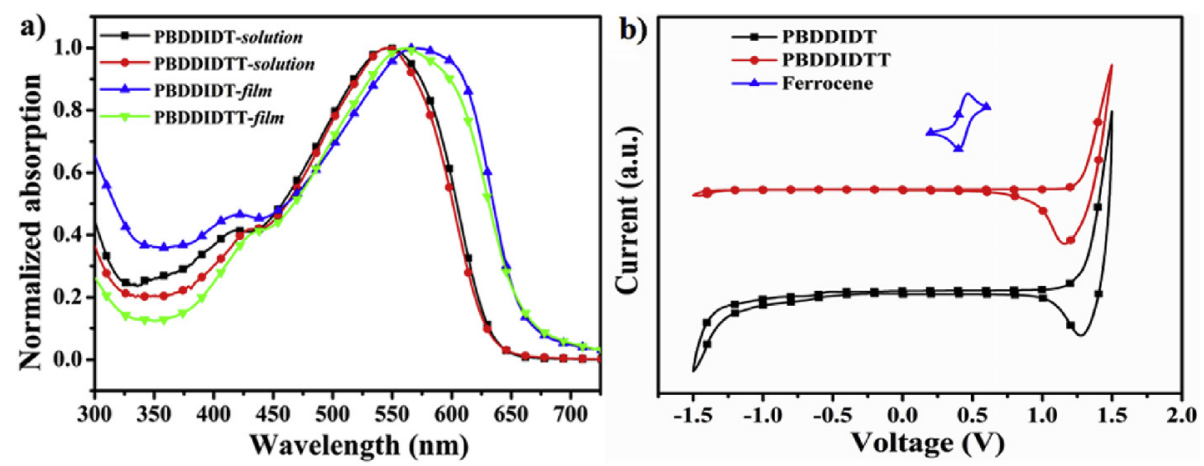

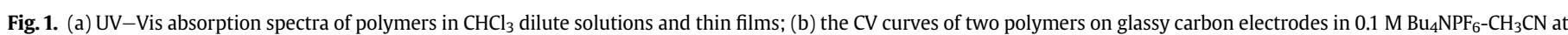
a scan rate of $100 \mathrm{mV} \mathrm{s}^{-1}$. 


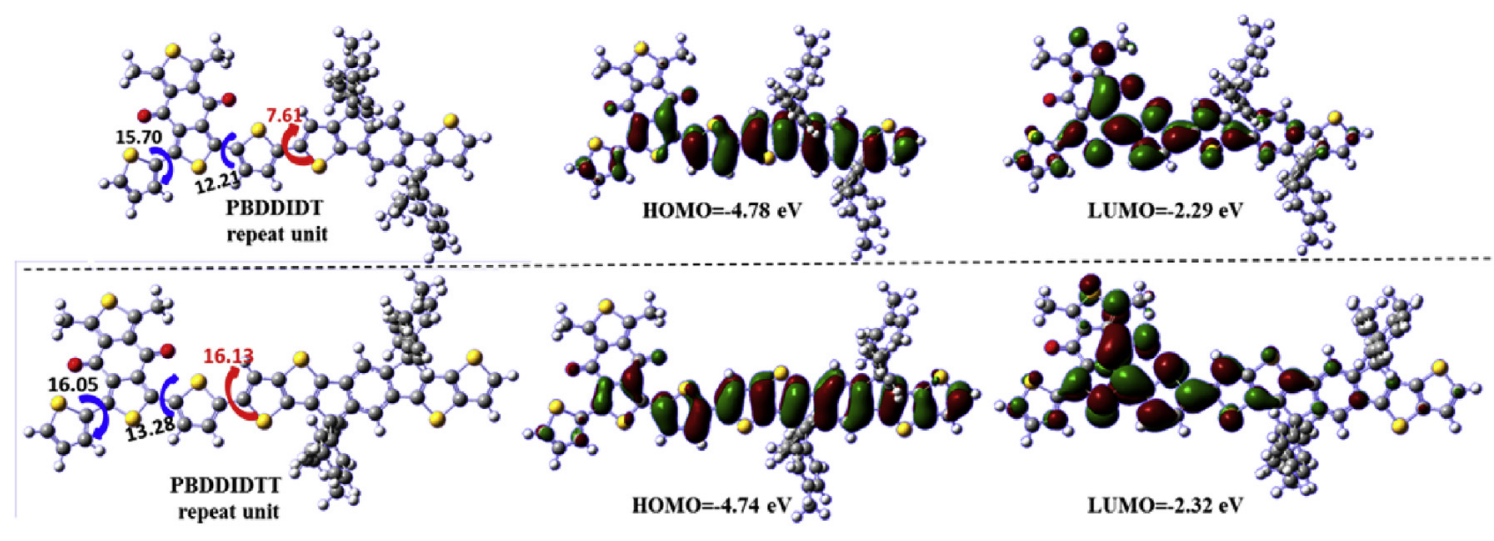

Fig. 2. Theoretically calculated model molecules, corresponding torsion angles, and calculated frontier energy levels of PBDDIDT and PBDDIDTT.

which should partially explain the slightly bule-shifted absorption spectra of PBDDIDTT compared to PBDDIDT. The distributions of HOMO and LUMO energy orbitals of two polymers are also shown in Fig. 2. The electron cloud of HOMO and LUMO frontier orbitals of PBDDIDT and PBDDIDTT are mainly distributed along the conjugated backbone proportionally, which would be beneficial to the charge carrier transport.

\subsection{Photovoltaic properties}

Polymer solar cells were prepared with polymer (PBDDIDT/ PBDDIDTT) as donor material and $\mathrm{PC}_{71} \mathrm{BM}$ as acceptor material and measured under AM $1.5 \mathrm{G}\left(100 \mathrm{~mW} \mathrm{~cm}^{-2}\right)$ illumination. As shown in Fig. 3a, the devices were fabricated with a configuration of indium tin oxide (ITO)/poly(3,4-ethylenedioxythiophene) polystyrene sulfonate (PEDOT:PSS)/polymer: $\mathrm{PC}_{71} \mathrm{BM} / \mathrm{PFN} / \mathrm{Al}$ and the energy level diagrams of materials in photovoltaic device are shown in Fig. 3b. Different polymer:PC ${ }_{71} \mathrm{BM}$ weight ratios $(w / w)$ were scanned from $1: 1$ to $1: 5$. The photovoltaic data were summarized in Table 2 and corresponding current density-voltage $(J-V)$ curves are shown in Fig. S4. As shown in Table 2, devices based on two polymers reveal similar varying tendency and the photovoltaic parameters of $J_{S C}$ and FF strongly depended on the D:A ratio. $V_{\mathrm{OC}}$ changes slightly with increase of acceptor content. While the values of $J_{\mathrm{SC}}$ and FF are improved markedly with the increase of acceptor content and reach the highest value for the devices with D/A $w /$ $w=1: 4$. Notably, optimal PSCs devices with rich acceptor content up to $80 \%$ are seldom reported. $J-V$ curves at the optimal weight ratios of two devices are shown in Fig. 3c, and the corresponding EQE curves exhibit broad response between 300 and $700 \mathrm{~nm}$ with the maximum values exceeding $70 \%$ (see Fig. 3d). Devices based on polymer PBDDIDT exhibit the best efficiency of $7.04 \%$ with $V_{\mathrm{OC}}=0.910 \mathrm{~V}, \mathrm{~J}_{\mathrm{SC}}=11.38 \mathrm{~mA} \mathrm{~cm}^{-2}$ and $\mathrm{FF}=0.68$. Devices based on polymer PBDDIDTT exhibit the optimal PCE of $6.40 \%$ with

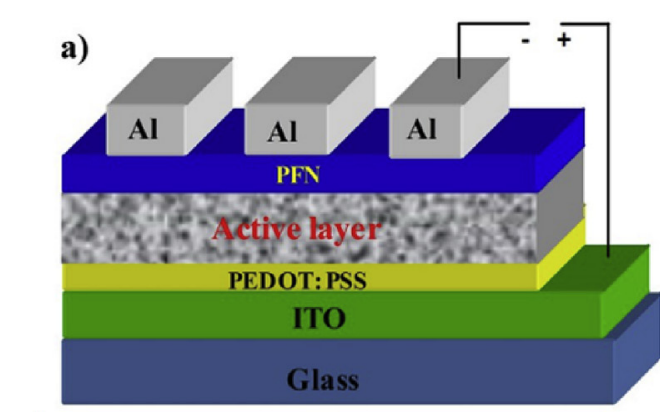

b)
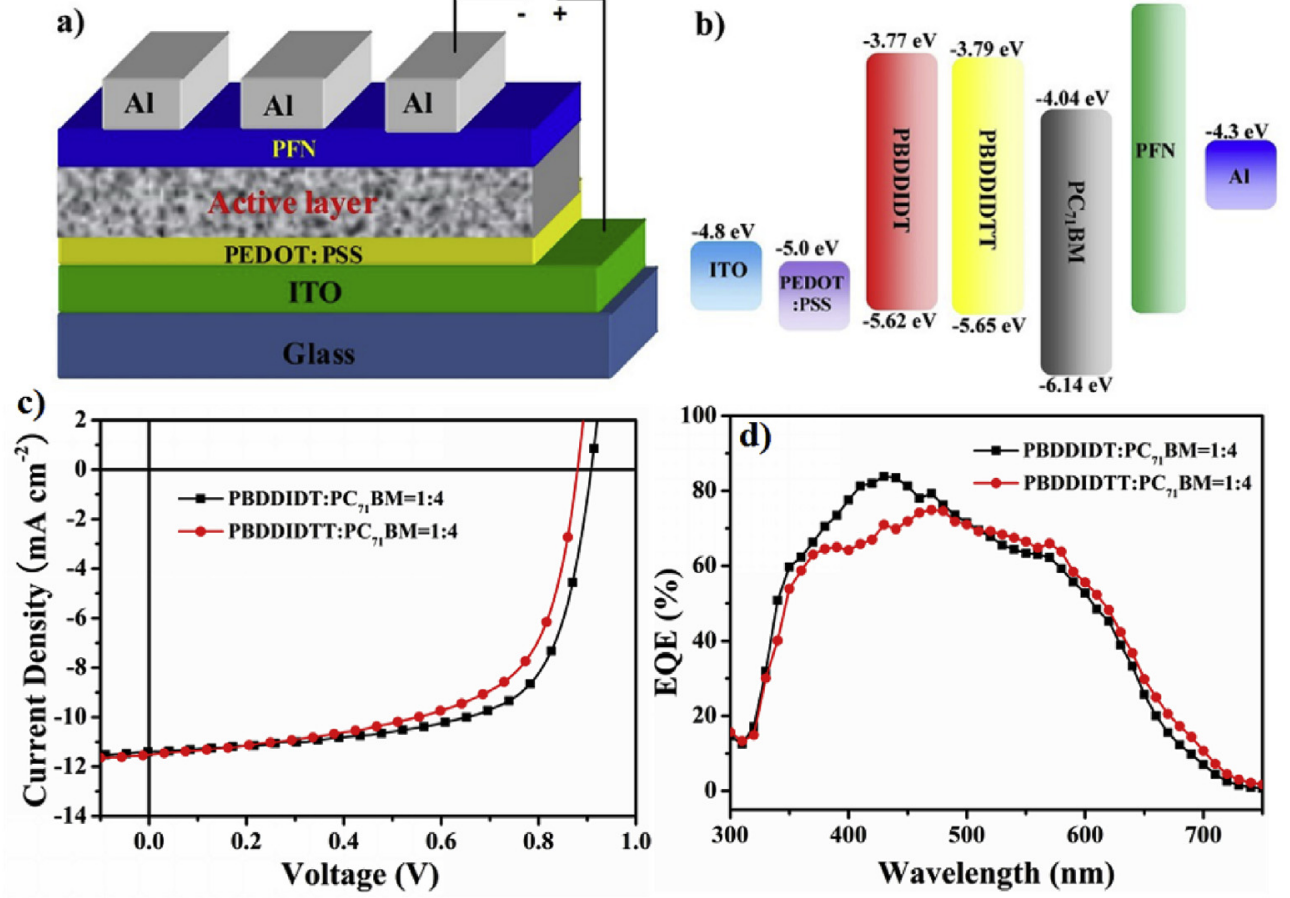

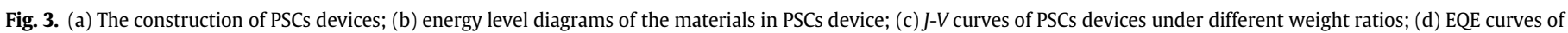
the corresponding PSCs. 
Table 2

Photovoltaic data of the PSCs based on polymer:PC $\mathrm{Pl}_{71} \mathrm{BM}$ with different weight ratios under the illumination of $\mathrm{AM} 1.5 \mathrm{G}$ at $100 \mathrm{mWcm}{ }^{-2}$.

\begin{tabular}{|c|c|c|c|c|c|c|c|c|c|c|}
\hline \multirow[t]{2}{*}{ Active layer } & \multirow[t]{2}{*}{$w / w$} & \multirow{2}{*}{$\begin{array}{l}V_{\mathrm{OC}} \\
\mathrm{V}\end{array}$} & \multirow{2}{*}{$\begin{array}{l}J_{\mathrm{SC}} \\
\mathrm{mA} \mathrm{cm}\end{array}$} & \multirow[t]{2}{*}{ FF } & \multirow{2}{*}{$\begin{array}{l}\text { PCE } \\
\%\end{array}$} & $R_{\mathrm{S}}^{\mathrm{a}}$ & $R_{\mathrm{Sh}}^{\mathrm{a}}$ & $\mu_{\mathrm{h}}^{\mathrm{b}}$ & $\mu \mathrm{e}^{\mathrm{b}}$ & \multirow[t]{2}{*}{$\mu_{\mathrm{h}} / \mu_{\mathrm{e}}$} \\
\hline & & & & & & \multicolumn{2}{|c|}{$\Omega \mathrm{cm}^{-2} \mathrm{k} \Omega \mathrm{cm}^{-2}$} & \multicolumn{2}{|c|}{$10^{-4} \mathrm{~cm}^{2} \mathrm{~V}^{-1} \mathrm{~s}^{-1}$} & \\
\hline \multirow{5}{*}{ PBDDIDT:PC ${ }_{71} \mathrm{BM}$} & $1: 1$ & 0.895 & 8.11 & 0.44 & 3.19 & 230 & 3.20 & 0.71 & 0.33 & 2.15 \\
\hline & $1: 2$ & 0.901 & 10.31 & 0.61 & 5.67 & 77 & 6.27 & 3.59 & 2.75 & 1.31 \\
\hline & $1: 3$ & 0.914 & 10.38 & 0.64 & 6.07 & 83 & 8.41 & 4.17 & 3.32 & 1.25 \\
\hline & $1: 4$ & 0.910 & 11.38 & 0.68 & 7.04 & 62 & 8.90 & 4.28 & 4.25 & 1.01 \\
\hline & $1: 5$ & 0.913 & 9.25 & 0.62 & 5.24 & 97 & 7.84 & 4.35 & 2.50 & 1.74 \\
\hline \multirow{5}{*}{ PBDDIDTT:PC ${ }_{71} \mathrm{BM}$} & $1: 1$ & 0.888 & 7.85 & 0.41 & 2.86 & 207 & 2.63 & 0.49 & 0.28 & 1.75 \\
\hline & $1: 2$ & 0.877 & 10.45 & 0.55 & 5.04 & 100 & 3.81 & 2.92 & 2.35 & 1.25 \\
\hline & $1: 3$ & 0.898 & 10.68 & 0.60 & 5.75 & 78 & 5.27 & 3.97 & 3.01 & 1.32 \\
\hline & $1: 4$ & 0.895 & 11.52 & 0.62 & 6.40 & 61 & 5.58 & 4.38 & 3.83 & 1.14 \\
\hline & $1: 5$ & 0.889 & 10.75 & 0.61 & 5.83 & 93 & 5.85 & 3.86 & 3.10 & 1.25 \\
\hline
\end{tabular}

a Data are obtained from $J$ - $V$ curves under illumination.

b Based on SCLC measurement.

$V_{\mathrm{OC}}=0.895 \mathrm{~V}, J_{\mathrm{SC}}=11.52 \mathrm{~mA} \mathrm{~cm} \mathrm{~cm}^{-2}$ and $\mathrm{FF}=0.62$. As shown in Table 2, the $V_{\mathrm{OC}}$ value of PBDDIDT device is slightly higher than that of PBDDIDTT. According to previous report, the maximum value of $V_{\mathrm{OC}}$ appears to be limited by the energy difference between the HOMO of the donor and the LUMO of the acceptor [50]. However, apart from this, different donor-acceptor distance, morphologies of active layers, device structures and many other factors can also affect $V_{\mathrm{OC}}$ [51]. As Table 2 reveals, PSCs based on PBDDIDT possess enhanced photovoltaic performance than PBDDIDTT, which is mainly attributed to the higher fill factors. As shown in Table S1, the additives including diiodooctane (DIO) and chloronaphthalene (CN) cannot produce a positive effect in this work.

The series resistance $\left(R_{\mathrm{S}}\right)$ and shunt resistance $\left(R_{\mathrm{Sh}}\right)$ of the PSCS are measured to understand the effect of polymer:PC ${ }_{71} B M$ weight ratios from their respective $J-V$ curves under illumination. As shown in Table 2, with the increase of weight ratio, $R_{\mathrm{S}}$ decreased and $R_{\mathrm{Sh}}$ increased gradually and reached the lowest $R_{\mathrm{S}}$ and highest $R_{\mathrm{sh}}$ values at $w / w=1: 4$, suggesting better overall diode characteristics at optimal conditions [52].

The exciton separation and charge transfer behavior in blend films with different D/A weight ratios is studied on the basis of photoluminescence (PL) spectra, since the charge separation and transfer efficiency can be inferred from the degree of PL quenching. As shown in Fig. 4, the PL emission of PBDDIDT and PBDDIDTT neat films are largely quenched by addition of $\mathrm{PC}_{71} \mathrm{BM}$ content. The quenching efficiencies are above $90 \%$ in the two blend films with $\mathrm{D} /$ A weight raito of $1: 1$. And the PL emission of neat films are nearly completed quenched when the D/A weight raito reached $1: 4$ with $\Phi_{\text {quench }}$ higher than $96.5 \%$, which indicates that very efficient exciton dissociation arises at the donor-acceptor interface [53].

To further investigate the charge transport efficiency of devices, we focus on the study of charge carrier mobilities, since charge mobility is considered to be one of the key parameters dominating the efficient charge transport to electrodes. Space-charge-limited current (SCLC) method was adopted to measure charge mobilities. The calculated hole and electron mobilities are summarized in Table 2 and the plots of the current density $v s$. voltage of devices are shown in Fig. S5. Fig. 4c and d demonstrate a more intuitive diagram of the hole mobilities, electron mobilities and mobility ratios values (hole/electron) in two PSCs devices as a function of D/A weight ratios. As Table 2, Fig. 4c and d shows, the hole mobilities and electron mobilities are simultaneously enhanced with the decrease of $\mathrm{D} / \mathrm{A}$ weight ratios from $1: 1$ to $1: 4$ and reduce slightly in $w / w=1: 5$. Meanwhile, the values of $\mu_{\text {hole }} / \mu_{\text {electron }}$ mobilities afford a balance in devices with $w / w=1: 4$. For PBDDIDT and PBDDIDTT based devices, the ratios of hole/electron mobilities were confirmed to be 1.01 and 1.14 , respectively. This concurrently improved and balanced hole and electron mobilities will definitely facilitate the charge transport to anode and cathode electrodes, and suppress bimolecular recombination and further maximize the photocurrent and fill factors of solar cells [54].

\subsection{Morphology study}

To explore the effect of the surface morphology of blend films on the photovoltaic performance of the two PSCs, AFM measurements by tapping-mode and TEM measurements were applied to study the surface morphology information and in-depth nature of the polymer/PC ${ }_{71} \mathrm{BM}$ blend films with different $\mathrm{D} / \mathrm{A}$ weight ratios $(1: 1$, $1: 4, w / w)$. As shown in Fig. 5a,b,e,f, PBDDIDT: $\mathrm{PC}_{71} \mathrm{BM}$ blend film with weight ratios (1:4) exhibits uniform and continuous crystalline domains with larger root-mean-square (RMS) roughness of $2.25 \mathrm{~nm}$ than film with weight ratios (1:1). Identical results were observed from TEM images (Fig. $5 \mathrm{i}-\mathrm{j}$ ). According to previous report, the increased RMS in uniform films would facilitate the charge transport agreement with the results of SCLC measurements [55]. For PBDDIDTT: $\mathrm{PC}_{71} \mathrm{BM}$ blend films, flat films with small and similar RMS were obtained. While the rich $\mathrm{PC}_{71} \mathrm{BM}$ blend film $(1: 4, w / w)$ presents more distinct continuous nanoscale phase separation from AFM phase images and uniform morphology (Fig. $5 \mathrm{~g}-\mathrm{h}$ ) with less defects from TEM results (Fig. $5 k-1$ ). From the results of AFM and TEM, it can be concluded that the content of $\mathrm{PC}_{71} \mathrm{BM}$ in blend films has great influence on the morphology of heterojunction, which will further influence the charge separation and transfer as well as the photovoltaic performance of PSCs.

\section{Conclusions}

In this work, we demonstrate efficient polymer solar cells based on two new wide band-gap polymers PBDDIDT and PBDDIDTT with balanced hole/electron mobilities tuned by the acceptor content in bulk heterojunction blend films. Polymers PBDDIDT and PBDDIDTT were synthesized by analyzing and coupling appropriate electrondonating moieties and electron-withdrawing moieties. Two polymers show similar absorption profiles which are synthetically determined by different polymer structures and molecular conformations. Polymer solar cells were prepared with $\mathrm{PC}_{71} \mathrm{BM}$ as acceptor material and polymers PBDDIDT or PBDDIDTT as donor material. The results show that two devices reach their optimal conditions with rich $\mathrm{PC}_{71} \mathrm{BM}$ content up to $80 \%$ in blend films, which is unusual reported in PSCs. Devices based on PBDDIDT and PBDIDTT reveal good photovoltaic performance with PCE of $7.04 \%$ and $6.40 \%$, respectively, free of any additives or annealing. Notably, the performance based on PBDDIDT represents one of the highest efficiencies achieved with IDT-based donor polymers. Exciton separation and charge transfer behaviors were investigated by PL 

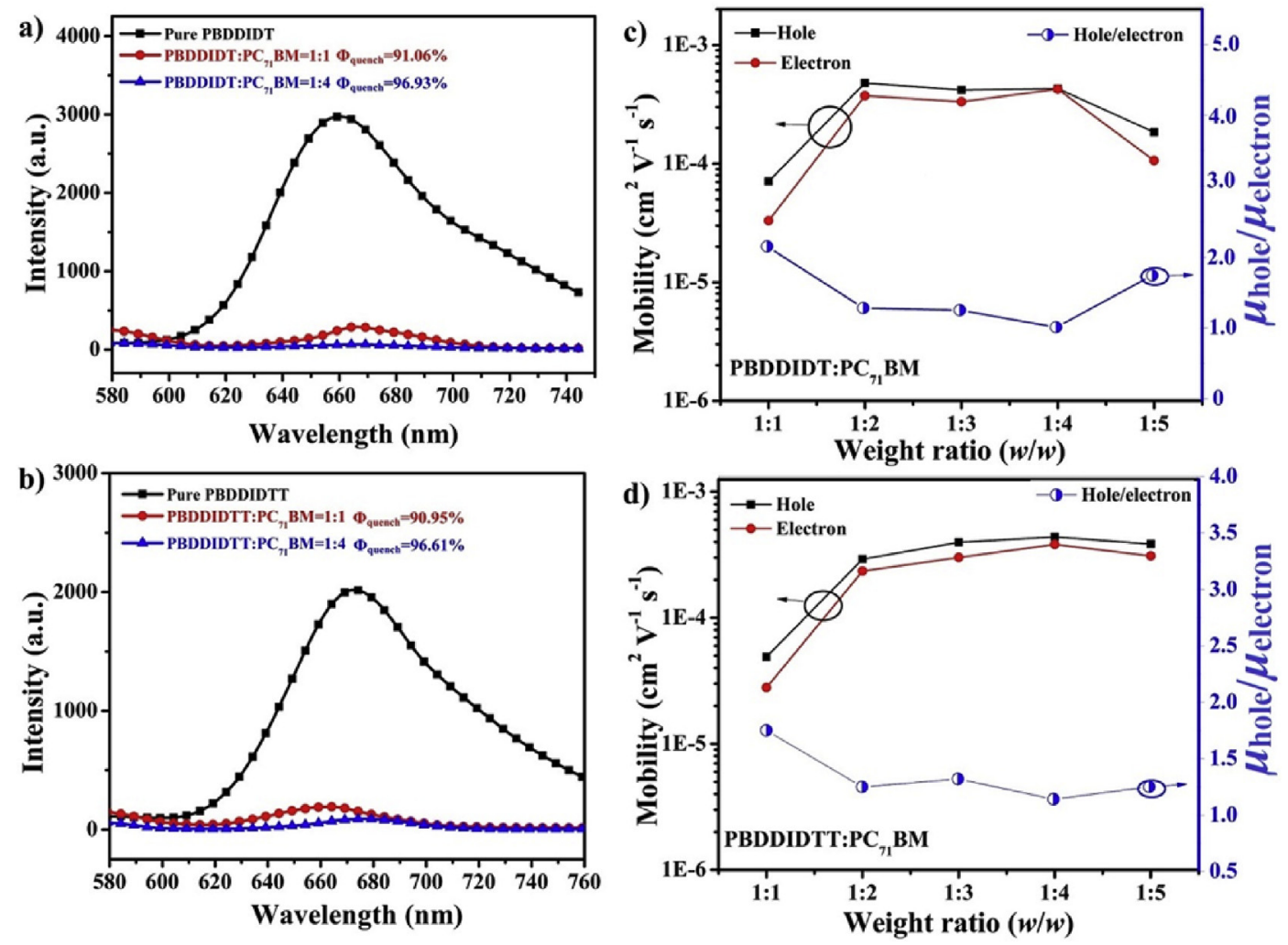

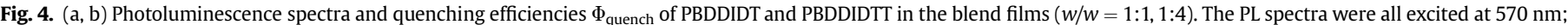

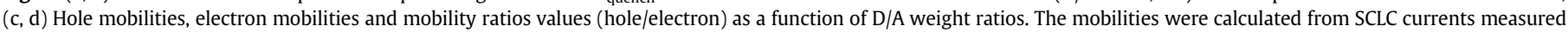
for the hole-only devices (ITO/PEDOT:PSS/active layer/ $\mathrm{MoO}_{3} / \mathrm{Al}$ ) and electron-only devices (ITO/ZnO/active layer/PFN/Al).

emission spectra and charge carrier mobilities in different $\mathrm{D} / \mathrm{A}$ weight ratios. The results of PL measurements show that fluorescence quenching efficiencies are enhanced in rich $\mathrm{PC}_{71} \mathrm{BM}$ blend films implying more efficient charge transport between polymer and $\mathrm{PC}_{71} \mathrm{BM}$. SCLC results exhibit that hole and electron mobilities were simultaneously enhanced and afford a good balance in rich $\mathrm{PC}_{71} \mathrm{BM}$ blend films (D/A, 1:4) and would benefit the improvement of $J_{S C}$ and FF. This work demonstrates two efficient WBG D-A conjugated photovoltaic polymers based on IDT and IDTT units and makes an instructive in-depth study about the influence of donor/ acceptor ratios to photovoltaic performance.

\section{Experimental section}

\subsection{Synthesis}

Acceptor materials $\mathrm{PC}_{71} \mathrm{BM}$ and monomers (IDT monomer and IDTT monomer) are purchased from Solarmer Materials Inc. All solvents and reagents were purchased from Alfa Aesar andTCI Inc, and utilized directly unless stated otherwise. Monomer 2BrBDD were synthesized according to previous report.

Synthesis of PBDDIDT: To a $25 \mathrm{~mL}$ flask, 2,8-bis(trimethyltin)indacenodithiophene (IDT monomer) $(123.3 \mathrm{mg}, 0.1 \mathrm{mmol})$ and 2BrBDD (76.7 mg, $0.1 \mathrm{mmol}$ ) were added to dry toluene $(4.5 \mathrm{~mL})$ and purged with argon for $30 \mathrm{~min}$. Then $\mathrm{Pd}\left(\mathrm{PPh}_{3}\right)_{4}(7.0 \mathrm{mg}$, $0.0055 \mathrm{mmol}$ ) were added and the solution was refluxed for $30 \mathrm{~h}$. After cooling to room temperature, the solution was poured into methanol $(100 \mathrm{~mL})$ and the polymer is filtered and subjected to Soxhlet extraction successively with methanol, acetone and hexane for the removal of remaining monomers, oligomers and catalytic impurities. The polymer was collected using $\mathrm{CHCl}_{3}$ as the eluent and precipitated against methanol. The residue was filtered and dried under vacuum for $24 \mathrm{~h}$ at $40^{\circ} \mathrm{C}$. Polymer PBDIDT was afforded as deep purple solids with a yield of $85 \%$. GPC: $M_{\mathrm{n}}=21.8 \mathrm{kDa}$, $\mathrm{PDI}=2.15 . T_{\mathrm{d}}=396{ }^{\circ} \mathrm{C}(95 \%$, nitrogen $) .{ }^{1} \mathrm{H}$ NMR $\left(600 \mathrm{MHz}, \mathrm{CDCl}_{3}, \delta\right.$ (ppm): 7.76-7.65 (m, 2H), 7.46-7.35 (m, 2H), $7.15(\mathrm{~m}, 18 \mathrm{H}), 3.33(\mathrm{br}$, $4 \mathrm{H}), 2.57(\mathrm{~s}, 8 \mathrm{H}), 1.77(\mathrm{~s}, 2 \mathrm{H}), 1.60(\mathrm{br}, 8 \mathrm{H}), 1.35-1.25(\mathrm{~m}, 35 \mathrm{H})$, $0.94-0.86(\mathrm{~m}, 24 \mathrm{H})$. Elemental analysis $\left(\mathrm{C}_{98} \mathrm{H}_{110} \mathrm{O}_{2} \mathrm{~S}_{6}\right): \mathrm{C} 77.87 \%, \mathrm{H}$ $7.58 \%$, S $12.47 \%$. Found: C 77.19\%, H 8.00\%, S $12.31 \%$.

Synthesis of PBDDIDTT:PBDDIDTT was synthesized according to the same procedure as PBDDIDT, except using the monomer 2,10bis(trimethyltin)-indacenodithieno[3,2- $b$ ]thiophene (IDTT monomer) $(134.5 \mathrm{mg}, 0.1 \mathrm{mmol})$. Polymer PBDDIDTT was obtained as deep purple solids with a yield of 92\%. GPC: $M_{\mathrm{n}}=25.6 \mathrm{kDa}$, PDI $=1.98 . T_{\mathrm{d}}=385{ }^{\circ} \mathrm{C}(95 \%$, nitrogen $) .{ }^{1} \mathrm{H}$ NMR $\left(600 \mathrm{MHz}, \mathrm{CDCl}_{3}, \delta\right.$ (ppm):7.72 (m, 2H), 7.56-7.42 (m, 4H), 7.22-7.10 (m, 16H), 3.34 (br, $4 \mathrm{H}), 2.57(\mathrm{~s}, 8 \mathrm{H}), 1.78(\mathrm{~s}, 2 \mathrm{H}), 1.60(\mathrm{br}, 8 \mathrm{H}), 1.46-1.22(\mathrm{~m}, 35 \mathrm{H})$, $1.03-0.70(\mathrm{~m}, 24 \mathrm{H})$. Elemental analysis $\left(\mathrm{C}_{102} \mathrm{H}_{110} \mathrm{O}_{2} \mathrm{~S}_{8}\right): \mathrm{C} 75.50 \%, \mathrm{H}$ 7.07\%, S 15.50\%. Found: C 75.05\%, H 7.32\%, S 16.25\%.

\subsection{Measurements and characterizations}

${ }^{1} \mathrm{H}$ NMR and ${ }^{13} \mathrm{C}$ NMR spectra were collected on a Bruker AVANCE-III 600 Spectrometer as solutions in $\mathrm{CDCl}_{3}$. The molecular weight of the polymers was measured by gel permeation chromatography (GPC) using tetrahydrofuran (THF) as the eluent $\left(40{ }^{\circ} \mathrm{C}\right)$. Thermalgravimetric analysis (TGA) measurement was carried out by STA- 409 at a heating rate of $10{ }^{\circ} \mathrm{C} / \mathrm{min}$. UV-vis absorption spectra were obtained using a Hitachi U4100spectrophotometer. PL spectra were measured using a 

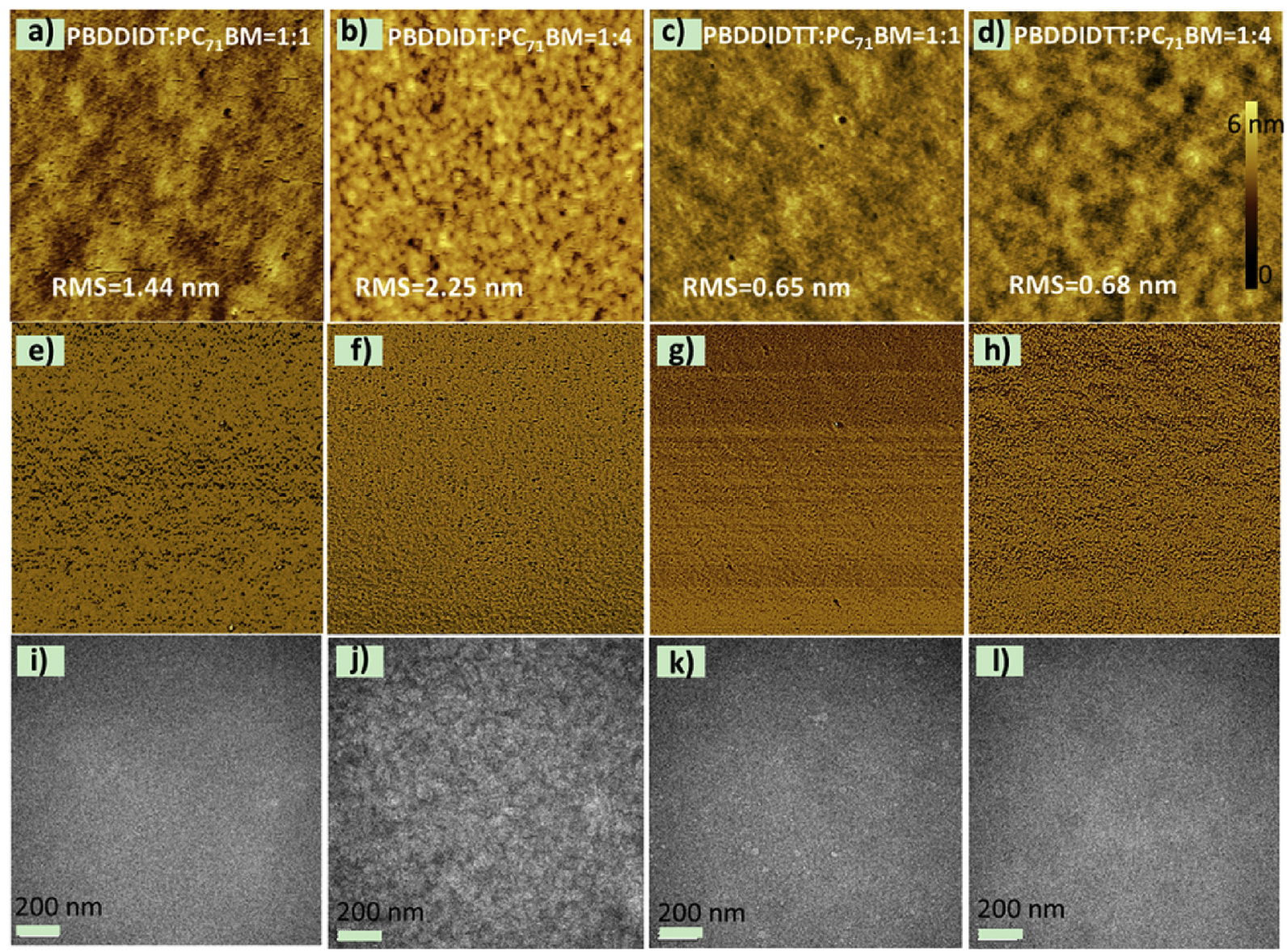

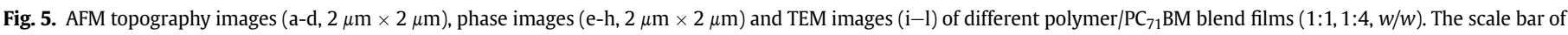
TEM images was $200 \mathrm{~nm}$.

Fluoromax-4 fluorescence spectrometer. Cyclic voltammetry (CV) measurements were recorded on a CHI660D electrochemical workstation with a three-electrode system. Density functional theory (DFT) calculations were confirmed by the Gaussian 09 program at the B3LYP/6-31G(d,p) level. Atomic force microscopy (AFM) images were obtained using Agilent 5400 scanning probe microscope in tapping-mode with MikroMasch NSC-15 AFM tips. Transmission electron microscopy (TEM) images were obtained by using a HITACHI H-7650 electron microscope with an acceleration voltage of $100 \mathrm{kV}$.

\subsection{Device fabrication and testing}

Photovoltaic devices were fabricated with a conventional device structure of ITO/PEDOT:PSS/polymer:PC ${ }_{71} \mathrm{BM} / \mathrm{PFN} / \mathrm{Al}$. The ITOcoated glass substrates were cleaned successively with detergent, deionized water, acetone and isopropanol, and dried with $\mathrm{N}_{2}$ flow. And then, the PEDOT:PSS layer was spin-coated onto the ITO from different weight ratios of donor and $\mathrm{PC}_{71} \mathrm{BM}$ blends in o-dichlorobenzene solution with different spin-coating speeds. The concentration of all blend solutions is $25 \mathrm{mg} / \mathrm{mL}$, and stirred overnight at room temperature before spin-coating the active layer. Then PFN solution (in $\mathrm{CH}_{3} \mathrm{OH}$ ) was spin-coating as electron transfer layer. Finally, aluminum ( $100 \mathrm{~nm}$ ) was evaporated onto the active layer at a vacuum of $\sim 2 \times 10^{-4}$ Pa to form the top electrode. The effective area of the device is $0.1 \mathrm{~cm}^{2}$. The current-voltage $(\mathrm{J}-V)$ characteristics were measured with a Keithley 2420 source measurement unit. The PSCs were measured under an irradiation intensity of
$100 \mathrm{~mW} / \mathrm{cm}^{2}$ (AM $1.5 \mathrm{G}$ ) by a Newport solar simulator. The EQE spectra were analyzed using a certified Newport IPCE measurement system. The hole and electron mobilities were calculated using the space charge limited current (SCLC) model with a device configuration of ITO/PEDOT:PSS/active layer/ $\mathrm{MoO}_{3} / \mathrm{Al}$ and ITO/ZnO/active layer/PFN/Al, respectively, where the current density is calculated by:

$\mathrm{J}=9 \varepsilon \mu \mathrm{V}^{2} /\left(8 \mathrm{~L}^{3}\right)$

where $\varepsilon$ represents the dielectric constant of the metal, and $\mu$ is the carrier mobility, $V$ is the voltage drop across the device and $L$ is the thickness of the active layer.

\section{Acknowledgements}

The authors are deeply grateful to the National Natural Science Foundation of China (21502205, and 51573205), the Ministry of Science and Technology of China (2016YFE0115000), and China Postdoctoral Science Foundation (2016T90656) for financial support.

\section{Appendix A. Supplementary data}

Supplementary data related to this article can be found at http:// dx.doi.org/10.1016/j.orgel.2017.08.031. 


\section{References}

[1] G. Yu, J. Gao, J.C. Hummelen, F. Wudl, A.J. Heeger, Polymer photovoltaic cells: enhanced efficiencies via a network of internal donor-acceptor heterojunctions, Science 270 (1995) 1789-1791.

[2] Y. Lin, Y. Li, X. Zhan, Small molecule semiconductors for high-efficiency organic photovoltaics, Chem. Soc. Rev. 41 (2012) 4245-4272.

[3] J. Zhou, X. Wan, Y. Liu, Y. Zuo, Z. Li, G. He, G. Long, W. Ni, C. Li, X. Su, Y. Chen, Small molecules based on benzo[1,2-b:4,5-b']dithiophene unit for highperformance solution-processed organic solar cells, J. Am. Chem. Soc. 134 (2012) 16345-16351.

[4] F.C. Krebs, Fabrication and processing of polymer solar cells: a review of printing and coating techniques, Sol. Energy Mater. Sol. Cells 93 (2009) 394-412.

[5] H. Hu, K. Jiang, G. Yang, J. Liu, Z. Li, H. Lin, Y. Liu, J. Zhao, J. Zhang, F. Huang, Y. Qu, W. Ma, H. Yan, Terthiophene-based D-A polymer with an asymmetric arrangement of alkyl chains that enables efficient polymer solar cells, J. Am. Chem. Soc. 137 (2015) 14149-14157.

[6] T. Kumari, S.M. Lee, S.-H. Kang, S. Chen, C. Yang, Aggregation and morphology control enables multiple cases of high-efficiency polymer solar cells, Energy Environ. Sci. 10 (2017) 258-265.

[7] V. Vohra, K. Kawashima, T. Kakara, T. Koganezawa, I. Osaka, K. Takimiya, H. Murata, Efficient inverted polymer solar cells employing favourable molecular orientation, Nat. Phot. 9 (2015) 403-408.

[8] J. Zhao, Y. Li, G. Yang, K. Jiang, H. Lin, H. Ade, W. Ma, H. Yan, Efficient organic solar cells processed from hydrocarbon solvents, Nat. Energy 1 (2016) 15027.

[9] Y. Jin, Z. Chen, S. Dong, N. Zheng, L. Ying, X.F. Jiang, F. Liu, F. Huang, Y. Cao A novel naphtho[1,2-c:5,6-c']bis([1,2,5]thiadiazole)-based narrow-bandgap pi-conjugated polymer with power conversion efficiency over 10, Adv. Mater. 28 (2016) 9811-9818.

[10] T. Liu, Y. Guo, Y. Yi, L. Huo, X. Xue, X. Sun, H. Fu, W. Xiong, D. Meng, Z. Wang, F. Liu, T.P. Russell, Y. Sun, Ternary organic solar cells based on two compatible nonfullerene acceptors with power conversion effciency $>10 \%$, Adv. Mater. 28 (2016) 10008-10015.

[11] L. Gao, Z.-G. Zhang, L. Xue, J. Min, J. Zhang, Z. Wei, Y. Li, All-polymer solar cells based on absorption-complementary polymer donor and acceptor with high power conversion efficiency of 8.27\%, Adv. Mater. 28 (2016) 1884-1890.

[12] P. Ma, C. Wang, S. Wen, L. Wang, L. Shen, W. Guo, S. Ruan, Small molecules based on tetrazine unit for efficient performance solution-processed organic solar cells, Sol. Energy Mater. Sol. Cells 155 (2016) 30-37.

[13] Z. Xu, Q. Fan, X. Meng, X. Guo, W. Su, W. Ma, M. Zhang, Y. Li, SeleniumContaining medium bandgap copolymer for bulk heterojunction polyme solar cells with high efficiency of 9.8\%, Chem. Mater. 29 (2017) 4811-4818.

[14] X. Cheng, Q. Wan, Y. Wu, B. Guo, X. Guo, Y. Li, M. Zhang, C. Cui, Y. Li, Toward high open-circuit voltage by smart chain engineering in 2D-conjugated polymer for polymer solar cells, Sol. Energy Mater. Sol. Cells 149 (2016) $162-169$.

[15] Y. Lin, J. Wang, Z.-G. Zhang, H. Bai, Y. Li, D. Zhu, X. Zhan, An electron acceptor challenging fullerenes for efficient polymer solar cells, Adv. Mater. 27 (2015) 1170-1174.

[16] Q. Wu, D. Zhao, A.M. Schneider, W. Chen, L. Yu, Covalently bound clusters of alpha-substituted PDI-rival electron acceptors to fullerene for organic solar cells, J. Am. Chem. Soc. 138 (2016) 7248-7251.

[17] C. Kitamura, S. Tanaka, Y. Yamashita, Design of narrow-bandgap polymers. Syntheses and properties of monomers and polymers containing aromatic donor and o-quinoid-acceptor units, Chem. Mater 8 (1996) 570-578.

[18] W. Li, W.S. Roelofs, M.M. Wienk, R.A. Janssen, Enhancing the photocurrent in diketopyrrolopyrrole-based polymer solar cells via energy level control, J. Am. Chem. Soc. 134 (2012) 13787-13795.

[19] J.D. Yuen, J. Fan, J. Seifter, B. Lim, R. Hufschmid, A.J. Heeger, F. Wudl, High performance weak donor-acceptor polymers in thin film transistors: effect of the acceptor on electronic properties, ambipolar conductivity, mobility, and thermal stability, J. Am. Chem. Soc. 133 (2011) 20799-20807.

[20] A.R. Han, G.K. Dutta, J. Lee, H.R. Lee, S.M. Lee, H. Ahn, T.J. Shin, J.H. Oh, C. Yang, $\varepsilon$-branched flexible side chain substituted diketopyrrolopyrrole-containing polymers designed for high hole and electron mobilities, Adv. Funct. Mater. 25 (2015) 247-254.

[21] J.W. Lee, H. Ahn, W.H. Jo, Conjugated random copolymers consisting of pyridine- and thiophene-capped diketopyrrolopyrrole as Co-Electron accepting units to enhance both $J_{\mathrm{SC}}$ and $V_{\mathrm{OC}}$ of polymer solar cells, Macromolecules 48 (2015) 7836-7842.

[22] K.H. Hendriks, G.H. Heintges, V.S. Gevaerts, M.M. Wienk, R.A. Janssen, Highmolecular-weight regular alternating diketopyrrolopyrrole-based terpolymers for efficient organic solar cells, Angew. Chem. 52 (2013) 8341-8344.

[23] K.H. Hendriks, W. Li, M.M. Wienk, R.A. Janssen, Small-bandgap semiconducting polymers with high near-infrared photoresponse, J. Am. Chem. Soc. 136 (2014) 12130-12136.

[24] Y. Liu, J. Zhao, Z. Li, C. Mu, W. Ma, H. Hu, K. Jiang, H. Lin, H. Ade, H. Yan, Aggregation and morphology control enables multiple cases of high-efficiency polymer solar cells, Nat. Commun. 5 (2014) 5293.

[25] W. Li, S. Albrecht, L. Yang, S. Roland, J.R. Tumbleston, T. McAfee, L. Yan, M.A. Kelly, H. Ade, D. Neher, W. You, Mobility-controlled performance of thick solar cells based on fluorinated copolymers, J. Am. Chem. Soc. 136 (2014) $15566-15576$.
[26] L. Han, H. Jiang, D. Ouyang, W. Chen, T. Hu, J. Wang, S. Wen, M. Sun, R. Yang, Cyclic alkyl chains promote the polymer self-assembly and packing orders for solar cells, Nano Energy 36 (2017) 110-117.

[27] Q. Liu, X. Bao, S. Wen, Z. Du, L. Han, D. Zhu, Y. Chen, M. Sun, R. Yang, Hyperconjugated side chained benzodithiophene and 4,7-di-2-thienyl-2,1,3 benzothiadiazole based polymer for solar cells, Polym. Chem. 5 (2014) 2076.

[28] M. Zhang, X. Guo, W. Ma, H. Ade, J. Hou, A large-bandgap conjugated polymer for versatile photovoltaic applications with high performance, Adv. Mater. 27 (2015) 4655-4660.

[29] D. Zhu, X. Bao, Q. Zhu, C. Gu, M. Qiu, S. Wen, J. Wang, B. Shahid, R. Yang, Thienothiophene-based copolymers for high-performance solar cells, employing different orientations of the thiazole group as a $\pi$ bridge, Energy Environ. Sci. 10 (2017) 614-620.

[30] D. Liu, Q. Zhu, C. Gu, J. Wang, M. Qiu, W. Chen, X. Bao, M. Sun, R. Yang, Highperformance photovoltaic polymers employing symmetry-breaking building blocks, Adv. Mater. 28 (2016) 8490-8498.

[31] D. Liu, C. Gu, J. Wang, D. Zhu, Y. Li, X. Bao, R. Yang, Naphthalene substituents bonded via the $\beta$-position: an extended conjugated moiety can achieve a decent trade-off between optical band gap and open circuit voltage in symmetry-breaking benzodithiophene-based polymer solar cells, J. Mater. Chem. A 5 (2017) 9141-9147.

[32] J. Lee, R. Singh, D.H. Sin, H.G. Kim, K.C. Song, K. Cho, A nonfullerene small molecule acceptor with 3D interlocking geometry enabling efficient organic solar cells, Adv. Mater. 28 (2016) 69-76.

[33] S. Li, L. Ye, W. Zhao, S. Zhang, S. Mukherjee, H. Ade, J. Hou, Energy-level modulation of small-molecule electron acceptors to achieve over $12 \%$ efficiency in polymer solar cells, Adv. Mater. 28 (2016) 9423-9429.

[34] H. Yao, Y. Chen, Y. Qin, R. Yu, Y. Cui, B. Yang, S. Li, K. Zhang, J. Hou, Design and synthesis of a low bandgap small molecule acceptor for efficient polymer solar cells, Adv. Mater. 28 (2016) 8283-8287.

[35] Y. Li, L. Zhong, F.-P. Wu, Y. Yuan, H.-J. Bin, Z.-Q. Jiang, Z. Zhang, Z.-G. Zhang, Y. Li, L.-S. Liao, Non-fullerene polymer solar cells based on a selenophenecontaining fused-ring acceptor with photovoltaic performance of $8.6 \%$, Energy Environ. Sci. 9 (2016) 3429-3435.

[36] Y.Z. Lin, Q. He, F.W. Zhao, L.J. Huo, J.Q. Mai, X.H. Lu, C.J. Su, T.F. Li, J.Y. Wang, J.S. Zhu, Y.M. Sun, C.R. Wang, X.W. Zhan, J. Am. Chem. Soc. 138 (2016) 2973-2976.

[37] M. Zhang, X. Guo, X. Wang, H. Wang, Y. Li, Synthesis and photovoltaic properties of $\mathrm{d}-\mathrm{a}$ copolymers based on alkyl-substituted indacenodithiophene donor unit, Chem. Mater. 23 (2011) 4264-4270.

[38] W. Zhao, S. Li, H. Yao, S. Zhang, Y. Zhang, B. Yang, J. Hou, Molecular optimization enables over 13\% efficiency in organic solar cells, J. Am. Chem. Soc. 139 (2017) 7148-7151.

[39] W. Gao, T. Liu, M. Hao, K. Wu, C. Zhang, Y. Sun, C. Yang, Dithieno[3,2-b:2',3'-d] pyridin-5(4H)-one based D-A type copolymers with wide bandgaps of up to $2.05 \mathrm{eV}$ to achieve solar cell efficiencies of up to $7.33 \%$, Chem. Sci. 7 (2016) $6167-6175$.

[40] C. Wang, X. Xu, W. Zhang, J. Bergqvist, Y. Xia, X. Meng, K. Bini, W. Ma, A. Yartsev, K. Vandewal, M.R. Andersson, O. Inganäs, M. Fahlman, E. Wang, Low band gap polymer solar cells with minimal voltage losses, Adv. Energy Mater. 6 (2016) 1600148.

[41] D. Dang, W. Chen, S. Himmelberger, Q. Tao, A. Lundin, R. Yang, W. Zhu, A. Salleo, C. Müller, E. Wang, Enhanced photovoltaic performance of indacenodithiophene-quinoxaline copolymers by side-chain modulation, Adv. Energy Mater. 4 (2014) 1400680.

[42] B. Yang, S. Zhang, Y. Chen, Y. Cui, D. Liu, H. Yao, J. Zhang, Z. Wei, J. Hou, Investigation of conjugated polymers based on naphtho[2,3-c]thiophene-4,9dione in fullerene-based and fullerene-free polymer solar cells, Macromolecules 50 (2017) 1453-1462.

[43] C. Duan, J.J. van Franeker, M.M. Wienk, R.A.J. Janssen, High open circuit voltage polymer solar cells enabled by employing thiazoles in semiconducting polymers, Polym. Chem. 7 (2016) 5730-5738.

[44] X. Guo, M. Zhang, J. Tan, S. Zhang, L. Huo, W. Hu, Y. Li, J. Hou, Influence of D/A ratio on photovoltaic performance of a highly efficient polymer solar cell system, Adv. Mater. 24 (2012) 6536-6541.

[45] Y. Ma, S.-C. Chen, Z. Wang, W. Ma, J. Wang, Z. Yin, C. Tang, D. Cai, Q. Zheng, Indacenodithiophene-based wide bandgap copolymers for high performance single-junction and tandem polymer solar cells, Nano Energy 33 (2017) 313-324.

[46] R.S. Ashraf, B.C. Schroeder, H.A. Bronstein, Z. Huang, S. Thomas, R.J. Kline, C.J. Brabec, P. Rannou, T.D. Anthopoulos, J.R. Durrant, I. McCulloch, The influence of polymer purification on photovoltaic device performance of a series of indacenodithiophene donor polymers, Adv. Mater. 25 (2013) 2029-2034.

[47] Y. Li, J. Wang, Y. Liu, M. Qiu, S. Wen, X. Bao, N. Wang, M. Sun, R. Yang, Investigation of fluorination on donor moiety of donor-acceptor 4,7-dithienylbenzothiadiazole-based conjugated polymers toward enhanced photovoltaic efficiency, ACS Appl. Mater. Interfaces 8 (2016) 26152-26161.

[48] Y. Li, Y. Yang, X. Bao, M. Qiu, Z. Liu, N. Wang, G. Zhang, R. Yang, D. Zhang, New $\pi$-conjugated polymers as acceptors designed for all polymer solar cells based on imide/amide-derivatives, J. Mater. Chem. C 4 (2016) 185-192.

[49] Y. Li, G. Zhang, Z. Liu, X. Chen, J. Wang, C.a. Di, D. Zhang, Alternating electron donor-acceptor conjugated polymers based on modified naphthalene diimide framework: the large enhancement of p-type semiconducting performance upon solvent vapor annealing, Macromolecules 46 (2013) 5504-5511.

[50] G. Dennler, N.S. Sariciftci, Flexible conjugated polymer-based plastic solar 
cells: from basics to applications, Proc. IEEE 93 (2005) 1429-1439.

[51] C.J. Brabec, A. Cravino, D. Meissner, N.S. Sariciftci, T. Fromherz, M.T. Rispens, L. Sanchez, J.C. Hummelen, Origin of the open circuit voltage of plastic solar cells, Adv. Funct. Mater. 11 (2001) 374-380.

[52] F. Jiang, W.C. Choy, X. Li, D. Zhang, J. Cheng, Post-treatment-Free solutionprocessed non-stoichiometric $\mathrm{NiO}(\mathrm{x})$ nanoparticles for efficient holetransport layers of organic optoelectronic devices, Adv. Mater. 27 (2015) 2930-2937.

[53] J. Lee, D.H. Sin, B. Moon, J. Shin, H.G. Kim, M. Kim, K. Cho, Highly crystalline low-bandgap polymer nanowires towards high-performance thick-film organic solar cells exceeding 10\% power conversion efficiency, Energy Environ. Sci. 10 (2017) 247-257.

[54] H. Bin, L. Gao, Z.-G. Zhang, Y. Yang, Y. Zhang, C. Zhang, S. Chen, L. Xue, C. Yang M. Xiao, Y. Li, 11.4\% Efficiency non-fullerene polymer solar cells with trialkylsilyl substituted 2D-conjugated polymer as donor, Nat. Commun. 7 (2016) 13651.

[55] O.K. Kwon, M.A. Uddin, J.H. Park, S.K. Park, T.L. Nguyen, H.Y. Woo, S.Y. Park, A high efficiency nonfullerene organic solar cell with optimized crystalline organizations, Adv. Mater. 28 (2016) 910-916. 